\title{
Physiological and Morphological Changes Over the Past 50 Years in Yield Components in Tomato
}

\author{
Tadahisa Higashide ${ }^{1,2}$ and Ep Heuvelink \\ Horticultural Supply Chains Group, Wageningen University, Marijkeweg 22, 6709 PG Wageningen, \\ The Netherlands
}

\begin{abstract}
Additional Index words. Solanum lycopersicum, dry matter, light use efficiency, extinction coefficient, partitioning, photosynthetic rate

Abstract. Greenhouse tomato (Solanum lycopersicum) yield in The Netherlands has increased tremendously over the past 50 years. The effects of breeding during this period were investigated. Eight Dutch cultivars and one typical current Japanese cultivar that were released over the past 50 years were compared in a short-term experiment conducted from summer to fall in The Netherlands. Fresh fruit yield of the Dutch cultivars significantly increased $\approx 0.9 \%$ per year with the year of release from 1950 to 2000 . Dry weight fruit yield of the Dutch cultivars also increased with the year of release, whereas the fruit dry matter content was not correlated with the year of release. Total dry matter production of plants increased with the year of release, and the dry matter partitioning to fruit was not correlated with the year of release. An increase in dry matter production was caused not by an increase in fraction of intercepted light, but by light use efficiency based on correlations between each of them and the year of release. The light extinction coefficient in the plant canopy decreased, whereas leaf photosynthetic rate increased significantly with the year of release. Although fresh fruit yield of the Japanese cultivar was lower than that of the modern Dutch cultivars, fruit dry matter content of the Japanese cultivar was higher than that of the Dutch cultivars. An increase in yield over the past 50 years in Dutch tomato was caused by an increase in light use efficiency resulting from a decrease in light extinction coefficient (a morphological change) and an increase in leaf photosynthetic rate (a physiological change).
\end{abstract}

Greenhouse tomato yield in The Netherlands has doubled from $30 \mathrm{~kg} \cdot \mathrm{m}^{-2}$ per year in the $1980 \mathrm{~s}$ to $60 \mathrm{~kg} \cdot \mathrm{m}^{-2}$ per year in 2005 (Kwantitatieve Informatie voor de Glastuinbouw, 2005). This increase in yield is caused by many factors, e.g., improvements in greenhouse transmissivity and developments in cultivation techniques such as longer cultivation, soilless culture, high wire training systems, $\mathrm{CO}_{2}$ enrichment, and environmental control by computers. Also, breeding for higher yielding cultivars would have played a role in this increase in yield. van der Ploeg et al. (2007) reported that yield of modern tomato cultivars under current conditions was $40 \%$ higher than that of old cultivars.

The genetic component in yield improvement has been investigated in several crops. Hay (1995) reported in his review that increases in yield of wheat (Triticum aestivum) and barley (Hordeum vulgare) over the past century was caused by increased harvest indices (short-stem cultivars). Abbate et al. (1998) also reported that the dry weight of spikes of Argentine wheat cultivars was related to partitioning to spikes, although yield was more closely related with the grain/spike ratio rather than the dry weight of spikes. Saitoh et al. (1993) reported that harvest indices of modern rice (Oryza sativa) cultivars were higher than those of old cultivars. Morrison et al. (1999) reported for soybean (Glycine max) cultivars released from the 1930s to

Received for publication 18 June 2009. Accepted for publication 31 July 2009. This research was supported by the National Agriculture and Food Research Organization in Japan.

We thank De Ruiter Seeds for providing the seeds of some cultivars and Yuko Higashide for helping with the measurements in this experiment.

${ }^{1}$ Guest researcher from National Agricultural Research Center for Western Region. Current address: National Agricultural and Food Research Organization, National Institute of Vegetable and Tea Science, Minaminakane 40-1, Taketoyo, Aichi 470-2351, Japan.

${ }^{2}$ Corresponding author. E-mail: ton@affrc.go.jp. the 1990s in Canada that the yield increased $0.5 \%$ per year from the 1930s and that this increase was related to increases in harvest index, photosynthetic rate, and stomatal conductance and a decrease in leaf area index (LAI). These reports show that an increase in yield in these crops by breeding is primarily related to an increase in harvest index rather than total biomass production.

However, Hay (1995) reported that an increase in yield of maize (Zea mays) by breeding was not related to harvest index but to total dry matter production. Tollenaar and Aguilera (1992) also reported that solar radiation use efficiency of modern maize cultivars was higher than that of old cultivars, although there were no differences in light extinction coefficient and light absorption by crops.

Ho (1996) reported that the yield of different types of tomatoes such as beef, cherry, and round tomatoes was determined by partitioning to the fruit. van der Ploeg et al. (2007) reported that partitioning to fruit of modern tomato cultivars was not higher than that of old cultivars, although there were differences among cultivars. van der Ploeg et al. also reported that an increase in the yield of modern tomato cultivars was caused by an increase in total dry matter production resulting from higher light use efficiency (LUE).

In the current work, we look for confirmation of this unexpected result. Our aim of this research is to investigate whether Dutch tomato cultivars that were released between 1950 and 2000 show an increasing trend in yield and altered yield components when grown under the same conditions. Because fresh yield and its components are determined by physiological and morphological factors such as leaf photosynthetic rate, light extinction coefficient, and LUE, we investigated the relationship between them in the short-term experiment conducted from summer to fall.

Total production value of tomato occupies first place among vegetables in Japan (Ministry of Agriculture Forestry and Fisheries of Japan, 2007). Although cultivation techniques 
have also been developed in Japan, the yield has not increased from the $1980 \mathrm{~s}$ and has remained at $\approx 30 \mathrm{~kg} \cdot \mathrm{m}^{-2}$ per year. To determine the physiological and/or morphological background of this low yield, we added a typical current Japanese cultivar to our research.

\section{Materials and Methods}

Eight Dutch tomato cultivars [Moneymaker (release in 1950), Premier (1960), Extase (1960), Sonatine (1975), Calypso (1982), Liberto (1988), Gourmet (1991), and Encore (2002)] and one Japanese cultivar [Momotaro Fight (2001)] were compared in a short-term experiment. All cultivars are indeterminate type and have medium-large round fruit. The seeds were sown in seed trays on 9 July 2007 and 2 weeks later transplanted in rockwool cubes. On 20 Aug. 2007, the plants were transplanted in 16 rows of a rockwool system, 30 plants per row, in a greenhouse compartment $(13 \times 12 \mathrm{~m})$ at Wageningen University in The Netherlands. Day and night temperatures were set at 17 and $13{ }^{\circ} \mathrm{C}$ until $56 \mathrm{~d}$ after transplanting, respectively. From 57 to $105 \mathrm{~d}$ after transplanting, the temperatures were set at 20 and $15{ }^{\circ} \mathrm{C}$, respectively. The experiment was conducted in the period 20 Aug. to $6 \mathrm{Dec}$. 2007, although tomatoes in The Netherlands are produced almost year-round. Planting density was 3.7 plants $/ \mathrm{m}^{2}$. Biological pest control was conducted during the experiment. Flowers were pollinated by an electric vibrator for the lowest three trusses and from the fourth truss onward by bumble bees (Bombus terrestris). Plants were trained and leaves pruned like in a modern practice. All plants were pinched at the height of the top of the training wire above the seventh to 10th truss on 5 Nov. 2007.

The experiment was conducted in two plots: three double rows per plot with four border rows. In the double rows, $60 \mathrm{~cm}$ between rows, $100 \mathrm{~cm}$ between double rows, 20 plants per cultivar per plot were planted (three cultivars per double row $\times$ three double rows). The nine cultivars were arranged to avoid the same location between each plot. Nine to 12 plants per cultivar were planted in border rows and they were not measured. Every 2 weeks, the number of leaves and stem length were observed on five plants, the number of trusses and flowers and fruit set were observed on eight plants, and the leaf length and width were observed on plants per cultivar per plot. We harvested mature fruit three times per week and measured the fresh and dry weight of them. We also measured leaf area, fresh and dry weight of leaves, stem, and fruit of two or four plants per cultivar per plot in destructive measurements at 21, 58, and 105 d after transplanting. Each plant that was measured in the destructive measurements was surrounded by two guard plants. We referred to leaf blade and petiole as leaf. Weights of mature and immature fruit were measured separately. We also measured soluble solids of fruit from the first to second trusses by a refractometer (PR-101; Atago, Tokyo, Japan).

Leaf photosynthetic rate and stomatal conductance $\left(g_{\mathrm{S}}\right)$ of upper matured leaves were measured twice on one leaf in five plants in each cultivar by a portable photosynthesis system (LI6400; LI-COR, Lincoln, NE) at $1500 \mu \mathrm{mol} \cdot \mathrm{m}^{-2} \cdot \mathrm{s}^{-1}$ photosynthetic photon flux $(P P F)$ and $1000 \mu \mathrm{mol} \cdot \mathrm{mol}^{-1} \mathrm{CO}_{2}$ at 35 or $36 \mathrm{~d}$ after transplanting. To obtain a photosynthesis light response curve in 'Gourmet' and 'Moneymaker', the photosynthetic rate of upper matured leaves was measured twice or four times on one leaf in each cultivar at $35 \mathrm{~d}$ after transplanting at $0,10,20$, 40, 60, 200, 300, 500, 1000, and $1500 \mu \mathrm{mol} \cdot \mathrm{m}^{-2} \cdot \mathrm{s}^{-1} P P F$ and
$1000 \mu \mathrm{mol} \cdot \mathrm{mol}^{-1} \mathrm{CO}_{2}$. Based on the relation between PPF and photosynthetic rate, we approximated photosynthetic curves with a nonrectangular hyperbolic curve:

$$
P=\left[\varphi I+P_{M}-\left\{\left(\varphi I+P_{M}\right)^{2}-4 \varphi I \theta P_{M}\right\}^{0.5}\right] / 2 \theta-R
$$

in which $P=$ photosynthetic rate, $I=P P F, P_{M}=$ maximum photosynthetic rate, $\varphi=$ initial slope, $\theta=$ degree of curvature, and $R=$ respiration rate (Thornley, 1976).

Light extinction in the plant canopy can be described by the equation: $I=I_{0} e^{-k L}$, in which $I=$ horizontal light strength in the plant canopy, $I_{0}=$ horizontal light strength above the canopy, $k=$ light extinction coefficient, and $L=$ cumulated LAI (Monsi and Saeki, 1953). To obtain light extinction coefficient in the plant canopy for each cultivar, we measured $P P F$ by a $P P F$ sensor (LI-191SA; LI-COR) at six different heights in the closed plant canopy of each cultivar at $39 \mathrm{~d}$ after transplanting: 4.0 to 5.7 LAI, 180 to $230 \mathrm{~cm}$ plant height. $P P F$ above the plant canopy was also measured and recorded by a $P P F$ sensor (LI190SA; LI-COR) and data recorder (NR-600; Keyence, Tokyo, Japan). Individual leaf area of each cultivar was obtained by regression equations: $A_{l}=a L_{l} W_{l}$, in which $A_{l}=$ leaf area (square centimeters), $a=$ the proportionality factor of each cultivar, $L_{l}=$ leaf length (centimeters), and $W_{l}=$ leaf width (centimeters). The regression equations $\left(R^{2}=0.89\right.$ to 0.96$)$ were obtained by a destructive measurement at $58 \mathrm{~d}$ after transplanting. Cumulated LAI from the top at six heights was calculated based on the individual leaf area and leaf number at that height. Light extinction coefficient was obtained as a slope in logarithmic regression of $P P F$ against cumulated LAI at the six heights.

Light use efficiency was calculated as a slope in linear regression of the total cumulative dry matter production against the integral of intercepted photosynthetic active radiation $(P A R)$ at three destructive measurements. Greenhouse transmissivity and fraction of $P A R$ were assumed to be $60 \%$ and $50 \%$ of global radiation, respectively (Kurata, 1994; Society Agricultural Meteorology of Japan, 1997). Daily intercepted PAR by plants of each cultivar was calculated based on LAI and the light extinction coefficient in each cultivar. Relative growth rate (RGR) was calculated as the difference in logarithm natural of total dry weight between two destructive measurements divided by the period between the two measurements. Leaf area ratio (LAR) and specific leaf area (SLA) were averaged over a period between the two measurements. Net assimilation rate (NAR) was calculated as RGR divided by LAR during the period. Leaf weight ratio (LWR) was calculated as LAR divided by SLA.

\section{Results}

Effect of breeding in Dutch cultivars. Harvest of fruit was started on 31 Oct. 2007 in 'Liberto' and 'Sonatine'; on 1 Nov. 2007 in 'Momotaro Fight'; on 2 Nov. 2007 in 'Calypso', 'Extase', 'Gourmet', 'Moneymaker', and 'Premier'; and on 6 Nov. 2007 in 'Encore', respectively. At the end of the experiment, $105 \mathrm{~d}$ after transplanting, fruit at the fifth truss in 'Liberto' and 'Gourmet', at the fourth truss in 'Calypso' and 'Sonatine', and at the third truss in the other cultivars were harvested. At that time, cumulative fresh weight of harvested fruit of 'Liberto' and 'Gourmet' was significantly $(P<0.001)$ higher than for the other cultivars and there was no significant difference in cumulative fresh fruit yield between the other 
cultivars (Fig. 1). LAI increased and reached at 2.7 to 3.6 and 4.4 to 6.2 at 21 and $58 \mathrm{~d}$ after transplanting, respectively. Because of pruning old leaves and pinching, LAI was at 2.8 to 3.5 at $105 \mathrm{~d}$ after transplanting (data not shown).

Figure 2 shows a component hierarchy contributing to an increase in tomato yield. An increase in fresh fruit yield is caused by an increase in dry weight yield and/or by a decrease in fruit dry matter content. Figure 3 shows differences in total fresh and dry weight of fruit including immature fruit (Fig. 3AB) and total dry weight production aboveground (Fig. 3D) between the cultivars, and these characteristics significantly increased with the year of release of the cultivars $\left(R^{2}=0.63\right.$, 0.60 , and $0.62 ; P=0.019,0.024$, and 0.021 , respectively). There was also a significant $(P<0.001)$ difference in fruit dry matter content between the cultivars, but this was not correlated with the year of release (Fig. 3C). Therefore, it was in large part the result of an increase in total dry matter production for an

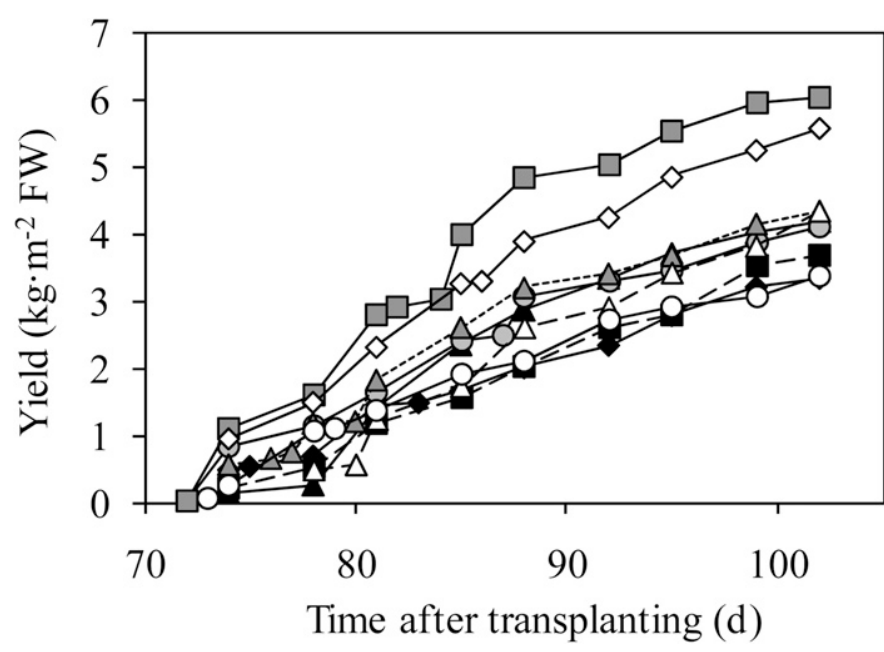

Fig. 1. Cumulative fresh fruit yield (mature fruit only) for nine tomato cultivars released in different years: Moneymaker $(\bullet)$, Premier $(\mathbf{\square})$, Extase $(\boldsymbol{\Delta})$, Sonatine (॰), Calypso $(\Delta)$, Liberto $(\square)$, Gourmet $(\diamond)$, Encore $(\Delta)$, and Momotaro Fight $(\mathrm{O})$.

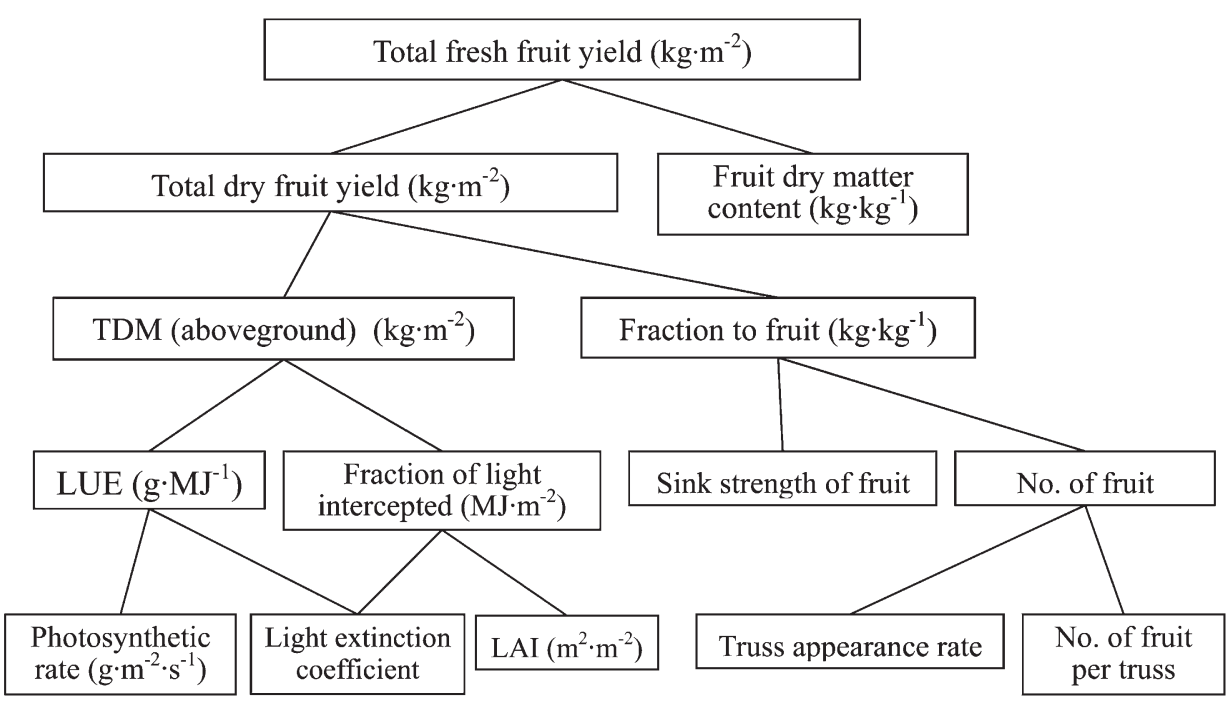

Fig. 2. Components contributing to an increase in fresh fruit yield in tomato: total dry matter production (TDM), light use efficiency (LUE), and leaf area index (LAI). increase in the fresh yield during the past 50 years and was not caused by a decrease in the fruit dry matter content. Increase in dry weight yield is determined by an increase in total dry matter production and/or fraction to the fruit (Fig. 2). There was also a significant $(P<0.001)$ difference between the cultivars in the dry matter fraction partitioned into fruit. However, this was not significantly correlated with the year of release (Fig. 3E). Therefore, an increase in yield was caused not by an increase in dry matter fraction partitioned into fruit.

Although truss, flower, and fruit number differed significantly $(P<0.001)$ between cultivars, there was no significant correlation between each of these parameters and the year of release (Fig. 4A-C). Fruit dry weight per fruit harvested (i.e., fruit size) was also not correlated with the year of release (Fig. 4D). Fruit set ratio (i.e., fruit number/flower number) differed significantly $(P<0.001)$ between cultivars and was positively correlated with the year of release $\left[R^{2}=0.65, P=0.016\right.$ (data not shown)].

Cultivars differed in RGR, LAR, LWR, and SLA $(P<0.05)$, except for SLA at $105 \mathrm{~d}$ after transplanting, but there was no significant correlation between each of these parameters and the year of release (data not shown). NAR during the period differed significantly $(P=0.015)$ between cultivars and was positively correlated with the year of release $\left(R^{2}=0.58, P=\right.$ 0.028 ). NAR is determined by LAI, light distribution characteristics such as structure of plant canopy and allocation of leaves, and leaf photosynthetic and respiration rate.

Total dry matter production is determined by LUE and/or by the fraction of intercepted light (Fig. 2). LUE differed significantly $(P<0.001)$ between cultivars and that of the Dutch cultivars was positively correlated with the year of release $\left[R^{2}=0.58, P=0.030\right.$ (Fig. 5A)]. In contrast, LAI at pinching, average LAI, and the fraction of intercepted light were not correlated with the year of release (data not shown). Therefore, an increase in total dry matter production was caused not by an increase in the fraction of intercepted light but by an increase in LUE. LUE is determined by light extinction coefficient and leaf photosynthetic rate (Fig. $2)$. Light extinction coefficient differed significantly $(P<0.001)$ between cultivars, and each of the coefficients was negatively correlated with the year of release $\left[R^{2}\right.$ $=0.66, P=0.014$ (Fig. 5B)]. In the photosynthesis light response curve of the old and modern cultivars (Fig. $6 \mathrm{~A})$, the maximum photosynthetic rate in modern cultivar Gourmet was significantly $(P<0.01)$ higher than that in old cultivar Moneymaker. The photosynthetic rate at 1500 $\mu \mathrm{mol} \cdot \mathrm{mol}^{-1} P P F$ also differed significantly $(P<0.001)$ between cultivars, and each of the rates was positively correlated with the year of release $\left[R^{2}\right.$ $=0.55, P=0.036$ (Fig. 6B)]. Thus, an increase in LUE was caused both by a decrease in the light extinction coefficient and an increase in the leaf photosynthetic rate. The $g_{\mathrm{S}}$ at 1500 $\mu \mathrm{mol} \cdot \mathrm{mol}^{-1} P P F$ also differed significantly $(P<0.001)$ between cultivars, being positively correlated with the year of release $\left[R^{2}=0.67, P=0.013\right.$ (data not shown)]. 

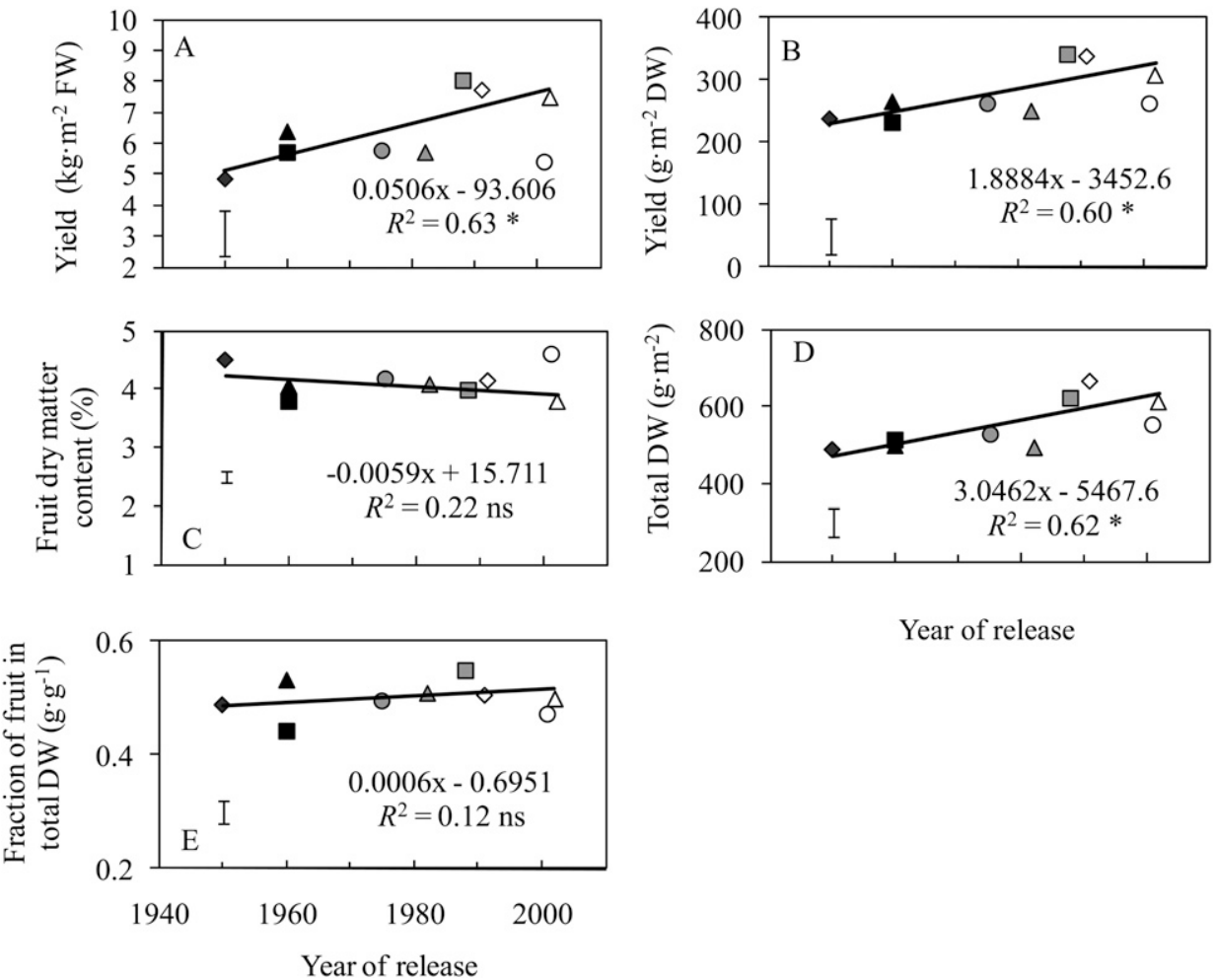

Fig. 3. Fresh weight yield (A), dry weight yield (B), fruit dry mater content (C), total dry weight production aboveground (D), and fraction of fruit in total dry weight $(\mathbf{E})$ for eight Dutch tomato cultivars [Moneymaker $(\bullet)$,

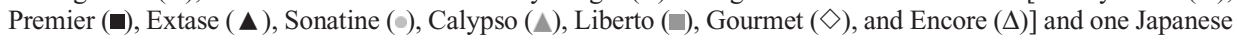
tomato cultivar [Momotaro Fight $(\bigcirc)$ ]. Yield in $\mathbf{A}$ and $\mathbf{B}$ included mature and immature fruit. Regression lines based on the data for the eight Dutch cultivars only. The error bar represents differences between cultivars by least significant difference at $P \leq 0.05$; ns $=$ not significant, *significant correlation at $P \leq 0.05$.
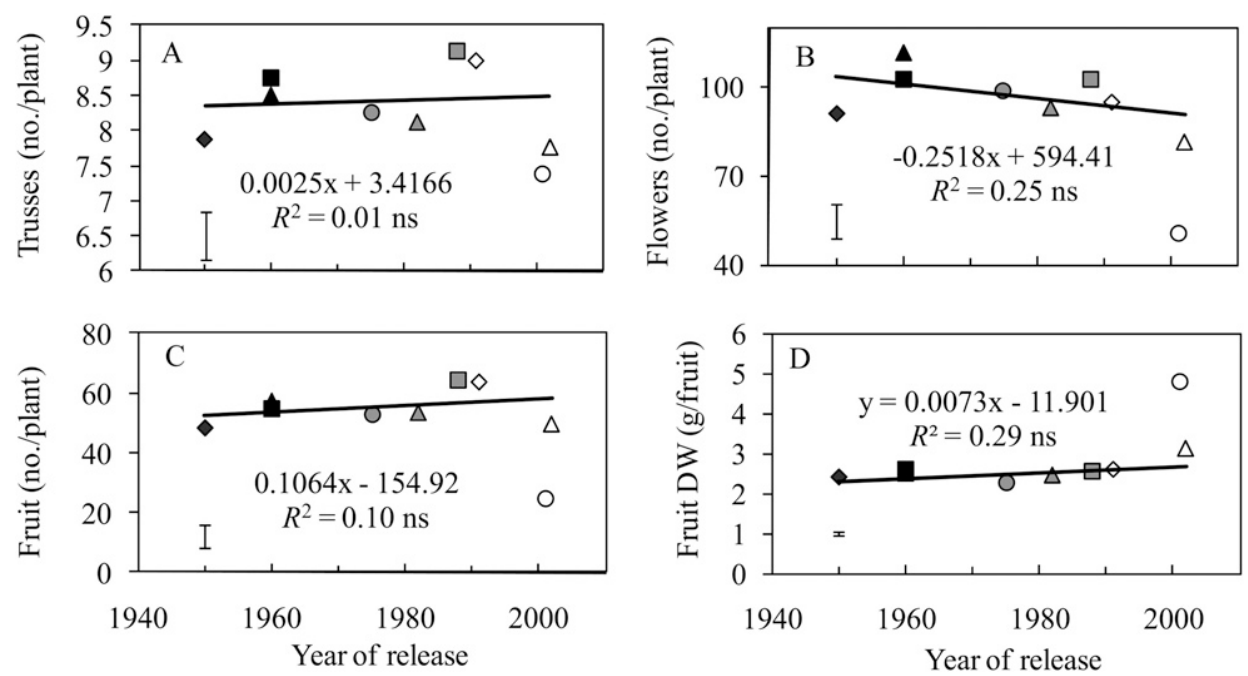

Fig. 4. Truss number (A), flower number (B), fruit number (C), and dry weight per fruit harvested (D) for eight

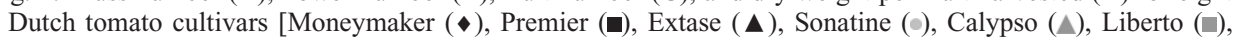
Gourmet $(\diamond)$, and Encore $(\Delta)$ ] and one Japanese tomato cultivar [Momotaro Fight $(\bigcirc)$ ]. Regression lines based on the data for the eight Dutch cultivars only. The error bar represents differences between cultivars by least significant difference at $P \leq 0.05$; ns $=$ not significant.

These results were also generally supported by correlations among the yield components of the Dutch cultivars (Table 1). Fresh fruit yield was not correlated with fruit dry matter content but correlated considerably with dry weight fruit yield. Fresh fruit yield was not correlated with dry matter fraction partitioned into fruit but correlated considerably with total dry matter production aboveground. Total dry matter production was not correlated with the fraction of intercepted light but considerably correlated with LUE. LUE was significantly and negatively correlated with light extinction coefficient. The correlation coefficient between LUE and photosynthetic rate was high, although there was no significant $(P=0.052)$ correlation between them. There was no significant correlation between the photosynthetic rate and each of the leaf parameters (SLA, LAR, and LWR; $r=-0.28,-0.58$, and -0.53 , respectively).

Differences BetWeen JAPANESE AND Dutch modern Cultivars. Fresh fruit yield of Japanese cultivar Momotaro Fight released in 2001 was lower than that of Dutch modern cultivar Encore released in 2002 (Fig. 3A). There was no significant difference in dry weight yield, total dry matter production, or dry matter fraction partitioned into fruit between 'Momotaro Fight' and 'Encore' (Fig. 3B, D, E). Fruit dry matter content of 'Momotaro Fight' was significantly $(P<0.001)$ higher than that of 'Encore' (Fig. 3C). Soluble solids of the Japanese cultivar were also significantly $(P<$ $0.001)$ higher than those of the Dutch cultivars except for Gourmet (data not shown). Although there was no significant difference in truss number between 'Momotaro Fight' and 'Encore', flower and fruit number and fruit set ratio of 'Momotaro Fight' were significantly $(P<0.001)$ lower than those of 'Encore' (Fig. 4).

\section{Discussion}

EFFect of BReEding IN DUTCH CUlTIVARS. Fresh fruit yield of Dutch cultivars increased $\approx 0.9 \%$ per year of release after 1950 (Fig. 3A). In the short-term experiment conducted in the spring, an increase in tomato yield as a result of breeding was caused not by an improvement in partitioning to the fruit but by an increase in total dry matter production and this increase in dry matter production was caused by higher LUE (van der Ploeg et al., 2007). The results from our experiment conducted from summer to fall support this finding (Fig. 3D-E; Table 1). An 
increase in yield of modern maize cultivars was related to increases in total dry matter production (Hay, 1995) and in solar radiation use efficiency (Tollenaar and Aguilera, 1992). Similarly, the increase in tomato yield by breeding was caused by increases in the dry matter production and in LUE.

Light extinction in the crop canopy can be described by the light extinction coefficient $(k)$, cumulative LAI $(L)$, and the equation: $I=I_{0} e^{-k L}$ (Monsi and Saeki, 1953). In a crop canopy
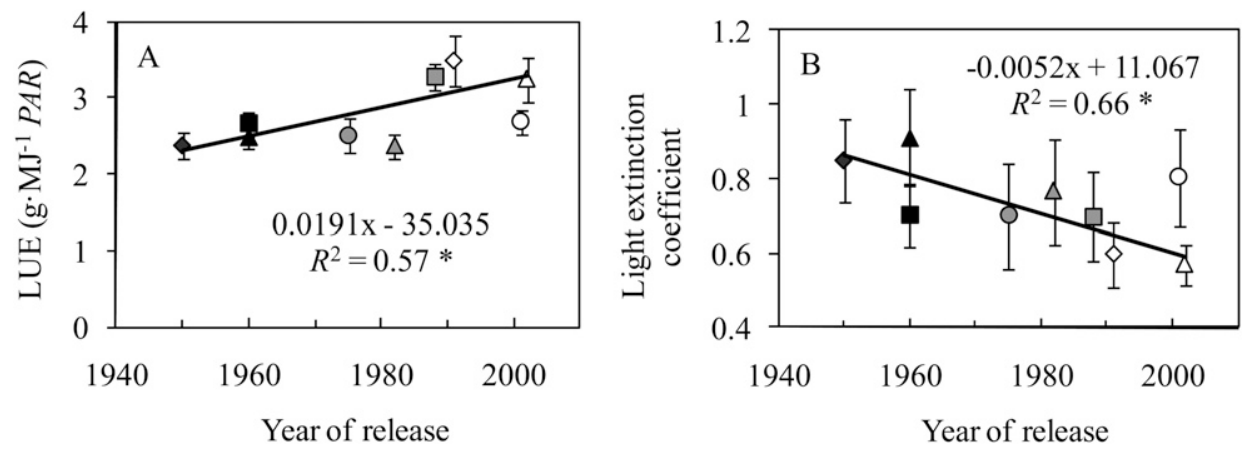

Fig. 5. Light use efficiency [LUE (A)] and light extinction coefficient (B) for eight Dutch tomato cultivars

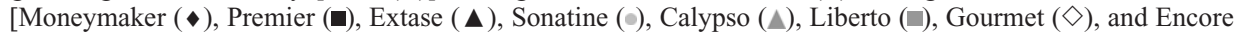
$(\Delta)$ ] and one Japanese tomato cultivar [Momotaro Fight $(\bigcirc)$ ]. Regression lines based on the data for the eight Dutch cultivars only. The error bar represents $95 \%$ confidence intervals; *significant correlation at $P \leq 0.05$.
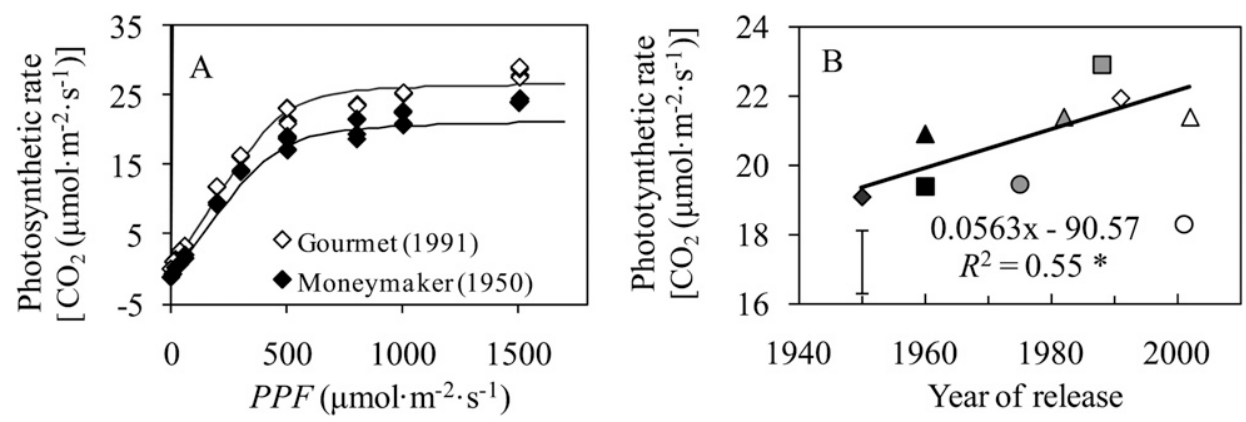

Fig. 6. Photosynthetic curve of individual leaves of old and modern tomato cultivars (A) and photosynthetic rate of

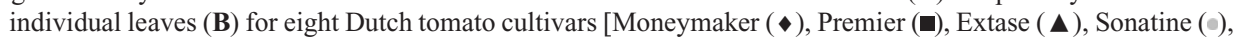
Calypso $(\Delta)$, Liberto $(\square)$, Gourmet $(\diamond)$, and Encore $(\Delta)$ ] and one Japanese tomato cultivar [Momotaro Fight (O)]. Regression line based on the data for the eight Dutch cultivars only. Measured at $1000 \mu \mathrm{mol} \cdot \mathrm{mol}^{-1} \mathrm{CO}_{2}$ (A-B), $1500 \mu \mathrm{mol} \cdot \mathrm{mol}^{-1}$ photosynthetic photon flux (B). Lines in A show approximation curve: $P=\left(\varphi I+P_{M}-\right.$ $\left.\left\{\left(\varphi I+P_{M}\right)^{2}-4 \varphi I \theta P_{M}\right\}^{0.5}\right) / 2 \theta-R$, in which $P=$ photosynthetic rate, $I=$ light intensity, $P_{M}=$ maximum photosynthetic rate, $\varphi=$ initial slope, $\theta=$ degree of curvature, $R=$ respiration rate. $P_{M}, \varphi, \theta$, and $R$ of 'Gourmet' and 'Moneymaker' are 29, 0.058, 0.97, and $0.134\left(R^{2}=0.99\right)$ and 25.5, 0.053, 0.96, and 1.24 $\left(R^{2}=0.98\right)$, respectively. The error bar in $\mathbf{B}$ represents differences between cultivars by least significant difference at $P \leq$ 0.05 ; *significant correlation at $P \leq 0.05$. that has a small $k$, light interception by lower leaves is higher than that in a large $k$ canopy. Therefore, if light intensity and are high, photosynthetic rate per plant in a small $k$ canopy 列 cultivars that had a high LAI and low $k$. LUE was negatively correlated with $k$ (Table 1 ). To clarify the effect of a decrease in $k$ on LUE, we simulated dry matter production at $k=0.85$ in the oldest cultivar and $k=0.57$ in the newest cultivar by TOMSIM (Heuvelink, 1995). LUE based on the simulation at low $k, 0.57$, was $\approx 15 \%$ higher $(2.53 \mathrm{~g} / \mathrm{MJ} P A R)$ than that at high $k, 0.85(2.20 \mathrm{~g} / \mathrm{MJ} P A R)$. The decrease in $k$ of the modern cultivars could contribute to an increase in LUE. LUE of the modern cultivars in our results was $\approx 40 \%$ higher than that of the old cultivars; LUE of the old and modern cultivars were 2.4 to 2.5 and 3.3 to $3.5 \mathrm{~g} / \mathrm{MJ}$ $P A R$, respectively (Fig. 5A). Leaf photosynthetic rate of the modern cultivars also increased in our experiments (Fig. 6). Thus, an increase in LUE would be caused not only by a decrease in $k$, but also by an improvement in leaf photosynthetic rate.

Some reports on cotton (Gossypium hirsutum), wheat, and rice imply that there was no difference in leaf photosynthetic rate between old and modern cultivars except during the reproductive growth period (Abbate et al., 1998; Kuroda and Kumura, 1990a; Rosenthal and Gerik, 1991; Saitoh et al., 1990) and that an increase in yield was caused mainly by a morphological change (Saitoh et al., 1993). An indeterminate type of tomato is still active in vegetative growth during the reproductive phase. In our experiment, leaf photosynthetic rates of the modern tomato cultivars were higher than those of the old cultivars

Table 1. Correlation coefficients between yield components, growth, and photosynthetic characteristics for the Dutch tomato cultivars released in different years.

\begin{tabular}{|c|c|c|c|c|c|c|c|c|}
\hline & $\begin{array}{c}\text { Yield dry } \\
\text { weight }\end{array}$ & $\begin{array}{c}\text { Fruit dry } \\
\text { matter content }\end{array}$ & $\begin{array}{c}\text { Total dry } \\
\text { weight } \\
\text { aboveground }\end{array}$ & $\begin{array}{c}\text { Fraction } \\
\text { to fruit }\end{array}$ & $\begin{array}{l}\text { Light use } \\
\text { efficiency }\end{array}$ & $\begin{array}{c}\text { Fraction of } \\
\text { intercepted light }\end{array}$ & $\begin{array}{l}\text { Light extinction } \\
\text { coefficient }\end{array}$ & $\begin{array}{c}\text { Photosynthetic } \\
\text { rate }\end{array}$ \\
\hline Yield fresh weight & 0.95 & -0.49 & 0.90 & 0.53 & 0.92 & -0.37 & -0.61 & 0.87 \\
\hline \multicolumn{9}{|l|}{ Total dry weight } \\
\hline aboveground & & & & 0.28 & 0.99 & -0.51 & -0.80 & 0.69 \\
\hline Significance & & & & NS & $* * *$ & NS & $*$ & NS \\
\hline Significance & & & & & & NS & $*$ & NS \\
\hline
\end{tabular}


(Fig. 6) at the vegetative growth period, although fruit growth was started. Thus, tomato would be different in this point from crops such as cotton, wheat, and rice.

Leaf photosynthetic rate is determined by the amount of photosynthetic protein per leaf area and $\mathrm{CO}_{2}$ conductance in stomata. To increase photosynthetic rate, plants have to increase the protein and/or the conductance. In our results, there was no significant correlation between the photosynthetic rate and each of the leaf parameter such as SLA, LAR, and LWR. However, Gosiewski et al. (1982) reported that photosynthetic rate in some tomato cultivars was not correlated with the $g_{\mathrm{S}}$ but rather with SLW and LAR. Kuroda and Kumura (1990b) reported that high leaf photosynthetic rate of modern rice cultivars during the reproductive growth period was caused by both high nitrogen content in leaves and high $g_{\mathrm{S}}$. Jiang et al. (1988) reported that rice cultivars of high leaf photosynthetic rate had well-developed roots. To clarify the cause of an increase in photosynthetic rate in modern tomato cultivars, a more detailed study is required.

Differences between Japanese and Dutch modern CULTIVARS. Fresh fruit yield and the number of fruit of Japanese cultivar were significantly lower than that of the modern Dutch cultivars (Figs. 3A and 4C). Because Japanese cultivar have improved by the breeding to be suitable for Japanese environmental condition such as high temperature, humidity, and solar radiation, the plants could not express their ability in Dutch environmental conditions. In tomato, there is a negative relationship between yield and total soluble solids (Stevens and Rudich, 1978). Sumida et al. (2008) reported that breeding objectives of Japanese cultivars Momotaro and its sister cultivars such as Momotaro Fight were sweetness, hardness and succulence of fruit, and short internodes of plants. Yield of the first 'Momotaro' that was released in 1985 was $\approx 80 \%$ of conventional cultivars at that time, although today, yield has been improved in its sister cultivars. In our results, there was no significant difference in dry weight yield, total dry weight production, and dry matter fraction partitioned into fruit between the Japanese cultivar and the latest Dutch cultivar Encore (Fig. 3B, D, E), whereas the fruit dry matter content (Fig. 3C) and soluble solids of the Japanese cultivar were significantly higher than those of the Dutch modern cultivars. Thus, these results might imply that fruit quality such as sweetness was better in the Japanese cultivar and that this was correlated with a lower total yield. Almost all fruit of tomato are consumed fresh in Japan. An improvement in fruit quality could have been more important for tomato breeding in Japan rather than an increase in yield.

\section{Literature Cited}

Abbate, P.E., F.H. Andrade, L. Lazaro, J.H. Bariffi, H.G. Berardocco, V.H. Inza, and F. Marturano. 1998. Grain yield increase in recent Argentine wheat cultivars. Crop Sci. 38:1203-1209.

Gosiewski, W., H.J.M. Nilwik, and J.F. Bierhuizen. 1982. The influence of temperature on photosynthesis of different tomato genotype. Scientia Hort. 16:109-115.

Hay, R.K.M. 1995. Harvest index: A review of its use in plant breeding and crop physiology. Ann. Appl. Biol. 126:197-216.

Hayashi, K. 1969. Efficiencies of solar energy conversion and relating characteristics in rice varieties. Jpn. J. Crop. Sci. 38:495-500.
Heuvelink, E. 1995. Dry matter production in tomato: Measurements and simulation. Ann. Bot. (Lond.) 75:369-379.

Ho, L. 1996. The mechanism of assimilate partitioning and carbohydrate compartmentation in fruit in relation to the quality and yield of tomato. J. Expt. Bot. 47:1239-1243.

Jiang, C., T. Hirasawa, and K. Ishihara. 1988. Physiological and ecological characteristics of high yielding varieties in rice plants. Jpn. J. Crop. Sci. 57:139-145 [in Japanese with English summary]. Kurata, K. 1994. Light environmental control, p. 233-242. In: S. Nishi, M. Amano, T. Itagi, T. Ito, I. Ueno, S. Okitsu, I. Kurata, T. Kozai, Y. Odaka, R. Sakiyama, K. Seike, T. Takakura, H. Hakura, and T. Murai. (eds.). Greenhouse horticulture handbook. 3rd Ed. Japanese Greenhouse Horticulture Assn., Tokyo, Japan [in Japanese].

Kuroda, E. and A. Kumura. 1990a. Difference in single leaf photosynthesis between old and new rice varieties. I Single leaf photosynthesis and its dependence on stomatal conductance. Jpn. J. Crop. Sci. 59:283-292 [in Japanese with English summary].

Kuroda, E. and A. Kumura. 1990b. Difference in single leaf photosynthesis between old and new rice varieties. III. Physiological bases of vertical difference in single-leaf photosynthesis between varieties viewed from nitrogen content and the nitrogen-photosynthesis relationship. Jpn. J. Crop. Sci. 59:298-302 [in Japanese with English summary].

Kwantitatieve Informatie voor de Glastuinbouw. 2005. Proefstation voor de bloemistrij en glasgroente (PGB). Kwantitatieve Informatie voor de Glastuinbouw, 2005-2006. Wageningen, The Netherlands.

Ministry of Agriculture Forestry and Fisheries of Japan. 2007. Survey of vegetables production and shipments, Crop survey. Ministry of Agriculture Forestry and Fisheries of Japan, Tokyo, Japan.

Monsi, M. and T. Saeki. 1953. Über den lichtfaktor in den pflanzengesellscaften und seine bedeutung für die stoffproduction. Jpn. J. Bot. 14:22-52.

Morrison, M.J., H.D. Voldeng, and E.R. Cober. 1999. Physiological changes from 58 years of genetic improvement of short-season soybean cultivars in Canada. Agron. J. 91:685-689.

Rosenthal, W.D. and T.J. Gerik. 1991. Radiation use efficiency among cotton cultivars. Agron. J. 83:655-658.

Saitoh, K., H. Shimoda, and K. Ishihara. 1990. Characteristics of dry matter production process in high yielding rice varieties. I. Canopy structure and light intercepting characteristics. Jpn. J. Crop. Sci. 59:130-139 [in Japanese with English summary].

Saitoh, K., H. Shimoda, and K. Ishihara. 1993. Characteristics of dry matter production process in high yielding rice varieties. VI. Comparisons between new and old rice varieties. Jpn. J. Crop. Sci. 62:509-517 [in Japanese with English summary].

Society of Agricultural Meteorology of Japan. 1997. Micrometeorological phenomena, p. 81-109. T. Maki, S. Iwata, Z. Uchijima, T. Oikawa, K. Omasa, K. Kurata, T. Kozai, E. Goto, H. Kon, I. Nouchi, Y. Harazono, T. Hoshi, H. Honjo, and S. Yamakawa. (eds.). Agricultural meteorology glossary. Society Agricultural Meteorology of Japan, Tokyo, Japan [in Japanese].

Stevens, M.A. and J. Rudich. 1978. Genetic potential for overcoming physiological limitation on adaptability, yield and quality in the tomato. HortScience 13:673-678.

Sumida, A., T. Kaya, and M. Hatanaka. 2008. Breeding and promotion of tomato cultivar 'Momotaro' resulted from innovation of its shipping and taste. Hort. Res. (Jpn.) 7:1-4 [in Japanese].

Thornley, J.H.M. 1976. Photosynthesis, p. 92-110. In: J.H.M. Thornley (ed.). Mathematical models in plant physiology. Academic Press, London, UK.

Tollenaar, M. and A. Aguilera. 1992. Radiation use efficiency of an old a new maize hybrid. Agron. J. 84:536-541.

van der Ploeg, A., M. van der Meer, and E. Heuvelink. 2007. Breeding for more energy efficient greenhouse tomato: Past and future perspectives. Euphytica 158:129-138. 